\title{
COMUNICACIÓN, CULTURA Y SINCRETISMO RELIGIOSO PARA UNA LECTURA INTERPRETATIVA DEL ARCÁNGEL SAN MIGUEL EN LA FIESTA DE LOS INDIOS CACIQUES DE CALBUCO (CHILE)
}

\author{
COMUNICATION, CULTURE AND RELIGIOUS SYNCRETISM FOR AN INTERPRETIVE \\ READING ON SAINT MIGUEL ARCHANGEL IN THE RELIGIOUS CELEBRATION DONE \\ BY ORIGINAL CACIQUES (MAPUCHES) FROM CALBUCO (CHILE)
}

\author{
Julio SÁEZ GALLARDO \\ Universidad San Sebastián, Puerto Montt (Chile) \\ julio.saez@uss.cl
}

Resumen: La presente investigación desarrolla una propuesta interpretativa acerca del Arcángel San Miguel, figura venerativa de la Fiesta de los indios caciques de Calbuco (Chile) y el proceso cultural de reinterpretación sincrética producido por los devotos de esta expresión de religiosidad popular. Para lo cual -desde una base teórico-crítica y empírica-se utilizan los aportes de la comunicación intercultural y el proyecto sociosemiótico (vinculado a una epistemología intercultural) de Miquel Rodrigo Alsina (1995).

Palabras clave: Arcángel San Miguel. Sincretismo religioso. Religiosidad popular. Devotos. Fiesta de los indios caciques de Calbuco (Chile). Sociosemiótica.

Abstract: The current research develops an interpretative proposal based on Saint Miguel Archangel, venerated figure by the Religious Celebration done by the Original Caciques (mapuches) from Calbuco (Chile) and its cultural interpretation produced by the popular religious expression. This work is based on a theorical-critical and empirical frame, given by Miquel Rodrigo Alsina's intercultural communication contribution and his social semiotic model.

KeyWords: Saint Miguel Archangel. Religious syncretism. Popular religions. Worshippers. Fiesta de los indios caciques de Calbuco (Chile). Social semiotic. 


\section{INTRODUCCIÓN: PLANTEAMIENTO DE UN PROBLEMA}

Las expresiones religiosas populares, como la veneración a los santos, por ejemplo, permanecen plenamente vigentes en la praxis religiosa en América Latina, las cuales han sido profusamente descritas e interpretadas. Diversos autores han abordado la religiosidad popular latinoamericana desde una lectura sincrética como línea dominante en los estudios de este fenómeno, el cual ha sido largamente interpretado en términos de la síntesis cultural que expresa. Al respecto, en el campo de la teoría social latinoamericana, puede mencionarse a Manuel Marzal (1983 y 2002) quien revisa las nociones de sincretismo religioso presente en numerosas investigaciones y propone una concepción renovada de la misma y, además, propone la tesis que la síntesis cultural latinoamericana, nuestro ethos, se produce en el plano del culto y la fiesta religiosa. Por otro lado, Alvarado Borgoño (1995) elabora un análisis de estas propuestas en su obra Sincretismo Religioso Latinoamericano y Pensamiento Católico. Similar perspectiva predomina en los estudios sobre el barroco latinoamericano (Mínguez, Rodríguez, González y Chiva 2012).

En tanto, otro grupo importante de autores han abordado la apropiación popular de la fe (sea católica u otra). Tal es el caso de Rostas y Droogers (1995) quienes estudian y comparan tres religiones populares brasileñas enfocando su análisis al uso popular que las personas hacen de las religiones. Martínez (2004), quien aborda los fenómenos de las apariciones marianas en Latinoamérica, intenta explicar las raíces socioculturales de la religiosidad popular en nuestro continente. Por su parte, en el ámbito de la religiosidad popular andaluza, Esther Fernández de Paz (2006) efectúa una reflexión teórico-crítica de las distintas manifestaciones que abundan en la aproximación religiosa popular sevillana. Finalmente, aludimos al análisis crítico que realiza Andrade (1997) de la religiosidad popular chilota, al interpretar desde los signos teatrales la fiesta religiosa de Jesús Nazareno de Caguach con el objetivo de determinar qué elementos teatrales son representativos dentro del proceso de comunicación y significación de la celebración cúltica icónica más representativa de las expresiones religiosas chilotas.

Dada la constatación del alto valor comunicacional y socioantropológico que revisten estas manifestaciones culturales, es que nos interesamos en esta investigación -desde una lectura interpretativa- dar cuenta del sentido atribuido y compartido por los feligreses, que desborda incluso lo planteado por la ortodoxia católica para estas manifestaciones de fe popular.

Aun cuando el clero intenta monopolizar la producción del discurso religioso, nos encontramos con un fenómeno de búsqueda y construcción de sentidos propios por parte de los feligreses que desafía la ortodoxia y la institucionalidad. Entonces, la pregunta central que recorre este trabajo -y que intentamos contestar- es ¿cómo interpreta 


\section{CALBUCO (CHILE)}

el devoto popular, a nivel discursivo, las estructuras simbólicas oficiales de la iglesia católica? Para contestar dicha interrogante nos hemos trazado como objetivo general: proponer desde lo empírico una lectura interpretativa de la apropiación de sentido acerca de la figura del Arcángel San Miguel producida por sus devotos, mediante el uso de la sociosemiótica para alcanzar el nivel de análisis y producir conocimiento teórico fundado en la vivencia de la religiosidad popular. En tanto, como objetivos específicos pretendemos: a) describir la fiesta religiosa en homenaje al Arcángel San Miguel, en Calbuco, como práctica comunicacional y, por ende, como práctica social, mediante la cual los fieles construyen, comparten y reinterpretan los sentidos, confiriéndole el carácter sincrético a esta expresión de cultura popular; b) determinar el proceso cultural de reinterpretación sincrética de la figura del Santo Patrono, mediante la aplicación de los componentes más relevantes del Modelo Sociosemiótico de Rodrigo Alsina.

A nivel de hipótesis, en primer lugar, sostenemos que la Fiesta de los indios caciques de Calbuco en homenaje al Arcángel San Miguel es una expresión de religiosidad popular sincrética tanto por su vertiente de conformación como por desarrollar en su seno un proceso cultural de reinterpretación y, en segundo lugar, afirmamos que el contraste (mediante una operación analítica contrastiva) entre las marcas semánticas del discurso dogmático referido a San Miguel y el discurso social de los devotos, confiere a este último un carácter reinterpretativo sincrético.

En consecuencia, nos proponemos en este artículo abordar, dadas las consideraciones precedentes, el proceso de reinterpretación sincrética elaborado por los fieles acerca del Arcángel San Miguel como santo venerativo de la festividad religiosa denominada Fiesta de los indios caciques de Calbuco (Chile), que se desarrolla todos los años en el mes de mayo en la citada ciudad del sur del país.

\section{CONTEXTUALIZACIÓN HISTÓRICA DEL RITO. LA SUBLEVACIÓN DE LOS INDIOS TRIBUTARIOS DE CALBUCO Y EL ARCÁNGEL SAN MIGUEL}

Al asumir como Gobernador del Reino de Chile, Juan Andrés de Ustáriz, nombra, en el año 1710, como Capitán del Fuerte de San Miguel de Calbuco a su antiguo criado, Alejandro Garzón de Garricochea. Además, le da poderes para asumir el gobierno de toda la Provincia de Chiloé, en caso de que el Gobernador propietario don José Marín de Velasco, sufriera alguna imposibilidad para ejercerlo.

A principios de 1712, Garzón entra en disputa con el Gobernador de Chiloé, don José Marín de Velasco y decide marcharse con sus tropas a Concepción, ciudad en que se encontraba por esa fecha el Gobernador Ustáriz, llevándose 62 soldados de infantería y unos 40 indios "reyunos" de Calbuco y, además, todas las armas, municiones y banderas 
de la plaza (Urbina Burgos, 1990) lo que debilitó drásticamente la defensa de la provincia. Los naturales aprovechando esta coyuntura se rebelan abiertamente en contra de los españoles, encontrando propicia ocasión para liberarse de la explotación de la cual eran objeto. La rebelión de los indios chilotes tributarios se produjo como una reacción frente a la encomienda que, a diferencia del resto del reino, se desenvolvía al arbitrio de los encomenderos quienes, por costumbre concebían la institución como servidumbre natural. La causa inmediata del suceso fueron los excesos e inconmensurables crueldades cometidas por el encomendero José de Andrade en contra de sus indios tributarios y -como señalábamos- la ocasión propicia: el abandono del fuerte de Calbuco por el capitán de Infantería, Alejandro Garzón, con la mitad de la tropa reglada de Chiloé (Urbina Burgos, 1990).

En efecto, el día 10 de febrero de 1712 se declararon en abierta rebelión y atacaron el indefenso Fuerte de San Miguel de Calbuco. Los sublevados dieron muerte a 13 o 14 españoles y una mujer, saquearon las casas y cometieron "todas las depravaciones ordinarias en estos levantamientos" (Barros Arana, 1909: 540). Según la tradición, además los indios insurrectos se llevaron, en calidad de botín de guerra, la imagen del Arcángel San Miguel, que estaba allí desde 1602 y que, según el Padre Miguel de Olivares (1874), los jesuitas lo trajeron desde el Perú convirtiéndolo en el Patrón y titular de la lglesia que levantaron en Santiago el año 1595. Sin embargo, la imagen plagiada del General de las milicias celestiales corresponde a la que fue transportada por el Padre Juan de Castellanos desde su convento en Osorno y llevada a la ciudad de Calbuco el año 1602, tras huir del asedio indígena de la ciudad de San Mateo de Osorno. Españoles e indígenas amigos osorninos llegaron a Calbuco el día de la Ascensión del Señor de 1602. Desde entonces, en esa fecha, se celebra la fiesta de San Miguel, en homenaje a este santo arcángel, en su calidad de patrono del fuerte que lleva su nombre en Calbuco (Vázquez de Acuña, 1994).

Para sofocar la rebelión indígena, el Gobernador de Chiloé, Marín de Velasco ordena al Maestre de Campo don Pedro de Molina Vasconcelos que acuda desde Concepción a Chiloé, acompañado de un poderoso destacamento. Según datos proporcionados por Barros Arana (1909) se habrían ajusticiado a más de ochenta naturales. En esta rebelión los indios reyunos no tomaron parte, pero sí en la represión de ella y así lo hace ver Tomás O'Higgins quien señala: "los indios de Calbuco se precian de haber sido fieles al soberano, tomando las armas contra los mismos naturales" (O'Higgins, 1949: 82)

Los misioneros jesuitas habrían servido de mediadores entre los indios y los españoles para que éstos devolvieran la tan preciada imagen de San Miguel. Tras largas tratativas los naturales la devuelven a su santuario como símbolo de acercamiento y paz, no sin antes negociar algunas concesiones. Entre las garantías que solicitaron los indios sublevados destaca aquella que anualmente en el homenaje que se rinde a San Miguel, ellos serían 


\section{CALBUCO (CHILE)}

los que manejarían el novenario, de acuerdo a sus costumbres y formas de adorar a Dios y al santo. El día de la Ascensión del Señor de 1712 los indios en una entrada masiva al fuerte devolvieron la imagen del Santo.

Según cuenta la tradición, desde esta fecha los diferentes caciques de las capillas del curato de San Miguel de Calbuco, elegían a un Cacique Principal, el cual dirigía y presidía las festividades para honrar al santo patrono. Esto implicaba que, al iniciarse la novena, este Cacique se hacía cargo del fuerte de Calbuco e incluso las autoridades debían ponerse bajo sus órdenes.

\section{BREVE DESCRIPCIÓN ETNOGRÁFICA DE LA FIESTA RELIGIOSA EN HOMENAJE AL ARCÁNGEL SAN MIGUEL}

\subsection{MISA DE DIANA}

La referida misa se lleva a cabo al amanecer del último día de la novena conmemorativa que rinde pleitesía a San Miguel. Es costumbre que una banda de músicos escolte desde su domicilio al Procurador de la fiesta hasta el templo, acompañados de un pequeño grupo de fieles, bajo los acordes del pasacalle de la marcha de los indios caciques. Una vez que han ingresado al templo los fiscales y patrones, acompañados de un buen número de fieles, se inicia la Adoración al Crucifijo, en un ambiente iluminado solo con la luz de las velas, otorgándole un carácter de profunda devoción y recogimiento espiritual al rito. Se ordenan en parejas los fiscales hacia la entrada del templo, ubicándose en primer plano el Procurador y el Fiscal Mayor. Estos se toman de las manos, en señal de gran unidad espiritual en torno a Cristo, avanzan entrelazados hasta el altar y luego se arrodillan y besan el suelo tres veces en señal de humildad y arrepentimiento. Besan la Cruz que yace en las escalinatas del altar, se persignan y depositan una contribución económica en los canastillos dispuestos para tal acción. Mientras los fieles cantan Jesús amoroso, se genera un ambiente suplicante y de arrepentimiento genuino, difícil de describir.

\subsection{PROCESIÓN DEL ARCÁNGEL SAN MIGUEL}

A través de la observación participante se aprecia que son recurrentes los distintos elementos que conforman el cosmos ritual de la fiesta en honor a San Miguel: las acciones rituales, el espacio sagrado, las imágenes de culto, la liturgia y los devotos. Todos ellos interactúan en forma constante y en diversa intensidad para conformar un todo textual de gran riqueza y espesura sígnica. Pero, solo a través de las acciones convencionalizadas es que se operacionaliza y se fusionan todos los componentes de este todo textual, 
mediante la asunción de rutinas no cotidianas que se materializan en movimientos gestuales y cánticos que encuentran su sentido profundo tanto en la liturgia oficial como en la tradición popular primigenia.

La procesión de homenaje a San Miguel Arcángel se encuentra imbuida de un característico espíritu gregario en torno a la imagen, si tenemos en cuenta que son alrededor de cuarenta comunidades eclesiales que se reúnen para honrar al Santo Patrono, portando su respectiva imagen de candelabro o santo de vestir. Ocasión que acompañan al festejado por las calles de la ciudad, confiriendo a la fiesta patronal un dominio icónico impresionante, dado por las vestimentas, el tamaño y aspecto casi viviente de la imaginería calbucana. Toda esta espectacular imagen escenográfica adquiere peso e importancia para la significación cultural del evento religioso popular.

En el acto procesional la imagen de San Miguel se localiza al final de las distintas veneraciones, lo que la tradición interpreta como una actitud de protección del santo arcángel hacia su pueblo. Se ve reforzada esta idea al portar la efigie una mano enhiesta con la espada con la que vence a Satanás. El General de las milicias celestiales y su cortejo de imágenes son paseados por las calles de Calbuco, mientras los devotos cantan alabanzas y rezos inherentes a cada devoción, generándose un ambiente sobrecargado de una espiritualidad sobria y reconcentrada, sin aspavientos de sacrificio corporal. Finalizado el recorrido, la imagen de San Miguel es puesta al costado del templo, en la vereda norte, a la espera del tributo que le rendirán los patrones de las distintas capillas a través del rito conocido como el batido de banderas.

\subsection{EL BATIDO DE BANDERAS}

El rito del batido de banderas es el que mayor condensación sígnica posee, puesto que observamos en este acto convencionalizado una abundante redundancia multimedial' que encuentra su esencia en cánones ceremoniales de antigua data. En este rito cobra protagonismo la figura del patrón cuya función es representar a la comunidad respectiva. Este se expresa mediante acciones corporales que se unen a elementos de distinta índole como signos icónicos (cruz, banderola, imágenes) además de signos verbales y audiovisuales (música, canto, insignias, tañido de campana). Todo este entramado sígnico apunta a darle un reforzamiento a la acción de batir bandera, creándose un fenómeno de redundancia sígnica que condensa al máximo la acción venerativa de homenaje,

1 Es la integración de diversos medios (visuales y auditivos) para la elaboración y envío de mensajes por diversos canales, potenciando la efectividad y la atracción de la comunicación al impactar más capacidades de recepción de la persona, mediante la reiteración, y de esta manera posibilitar la eliminación de barreras que puedan impedir el recibimiento del mensaje y su posterior impacto. 


\section{CALBUCO (CHILE)}

cobrando por tanto una especial peeminencia la figura de Cristo y de San Miguel, objetos de tributo.

Para la ceremonia ritual del batido de banderas se ubican en lugar visible y destacado el párroco, las autoridades que dirigen el novenario y los fiscales que tienen por misión cantar el himno del Ejército de San Miguel, rodeados por una multitud de fieles y curiosos. En un extremo de la calle se sitúa la imagen de Cristo y en la otra, la efigie del Arcángel San Miguel. Mientras los patrones en parejas baten las banderas, los fiscales y concurrencia cantan el himno de San Miguel: cada estrofa coincide con el batido de banderas de cada capilla y para todos se repite el estribillo: "suenen clarines, retumben las cajas / batan las banderas de nuestro Patrón / que luzca y que brille/como el mismo sol". Los patrones, en parejas y en forma alternada, se persignan, arrodillan y baten sus banderolas frente a Cristo y San Miguel respectivamente.

El batido de banderas se realiza dibujando en el aire una especie de número ocho, haciendo luego tres genuflexiones que se inician siempre con la rodilla derecha. Esto se repite para cada imagen. Una vez que todos los patrones rinden su homenaje se termina la novena de veneración a San Miguel, la que se repetirá cíclicamente todos los años, debido al "compromiso" asumido por los fieles con la tradición.

\section{MARCO TEÓRICO}

Se hace indispensable en este marco referencial plantear, sucintamente, cuál es la lógica que sustenta nuestra aproximación teórica hacia el fenómeno que pretendemos abordar como práctica comunicacional y, en consecuencia, como praxis social: la fiesta religiosa en honor a San Miguel Arcángel, en Calbuco.

En primer lugar, nos ocupamos de desarrollar el enfoque teórico-comunicacional que hemos utilizado para estudiar el proceso cultural reinterpretativo vinculado al Santo Patrono de Calbuco, el Arcángel San Miguel. En segundo lugar, constatamos el fenómeno de laxitud o deriva en que ha devenido el concepto de rito y que, por tanto, nos ofrece la posibilidad de entenderlo desde un enfoque más amplio: como un proceso de comunicación. En tercer lugar, hemos vinculado al rito comunicativo con el fenómeno cultural de la religiosidad popular, por cuanto estimamos que estos dos conceptos se encuentran indefectiblemente unidos. En cuarto lugar, construimos un entramado conceptual que sea capaz de darle un sustento teórico y comprensivo a la manifestación religiosa en adoración a la figura del Santo Patrono de la ciudad de Calbuco y el proceso de reinterpretación generado por los devotos. Para ello planteamos, en primer orden, la necesidad de concebir estas expresiones culturales como procesos comunicativos poniendo de relevancia que la fiesta religiosa, por un lado, es sincrética en sus orígenes, pues se amalgaman elementos de la matrices hispano-lusitanas y aborígenes generando 
una expresión sintética y, por otro, su éxito estriba en lo comunicativo, en el sentido que es capaz de acoger la multivocidad, el pluralismo en los usos e interpretaciones y abrirse a diversas formas de apropiación de sentido, fenómeno que de acuerdo a Bajtin (1989) se puede denominar heteroglosia. En segundo orden, explotamos aquí la noción de interpretación que en la tradición comprensiva que desemboca en la antropología simbólica (Geertz, 2000) designa la lectura de los fenómenos culturales desde la perspectiva de los actores.

El marco teórico referencial que adoptamos en este trabajo es el de los postulados y enfoques de la semiótica, en especial los aportes del semiólogo italiano Umberto Eco $(1981,1988)$. Desde este enfoque semiótico, anclamos nuestra mirada en los procesos de construcción de significaciones y sentidos compartidos, adoptando los aportes de la sociología del conocimiento con su concepto de construcción social de la realidad (Berger y Luckmann, 1979). Finalmente, desarrollamos el Modelo sociosemiótico propuesto por Miquel Rodrigo Alsina (1995), constructo que se aplica en el transcurso de nuestro trabajo, pues nos posibilita el acceso a una lectura interpretativa de la figura del Santo Patrono de Calbuco.

En cuanto a los desarrollos más recientes sobre nuestro objeto de estudio, o el estado de arte de esta festividad, mencionamos la obra del autor calbucano, Esteban Barruel (1997), Los fiscales de Chiloé. Una ruta devocional, que provee una exhaustiva descripción de la misma y de la institucionalidad de los fiscales, comprometida en ella; el Libro Historial de la parroquia de Calbuco, del sacerdote y ex párroco local Juan José Bergenhenegouwen (s.a.), manuscrito inédito disponible en el archivo parroquial, que provee numerosos antecedentes sobre la tradición histórica de la fiesta; el libro de padre Eduardo Tampe (1983) Desde Melipulli hasta Puerto Montt: Trayectoria de ciento treinta años, que provee descripciones que permiten ver la trayectoria de la fiesta; el artículo del comunicólogo Víctor Hugo Valenzuela (2005), “San Miguel Arcángel y la Serpiente: Comunicación e Interpretación de las Manifestaciones Culturales Arcaicas de nuestra Sociedad", que aborda precisamente los problemas de interpretación en torno a la figura del Arcángel; el libro del antropólogo Rodrigo Moulián (2010) Gozos de Santo: Fiesta, Ecumenismo y Heteroglosia, que muestra las diversas formas de apropiación de sentido en las fiestas del área, incluida la de Calbuco; la etnografía multimedia producida por el Instituto de Comunicación Social de la Universidad Austral de Chile (2008), El Rostro Indígena de San Miguel Arcángel, que destaca la tradición mestiza de esta fiesta. 


\section{CONSIDERACIONES METODOLÓGICAS}

En lo que refiere a la metodología, optamos por el estudio cualitativo de casos. Este es un tipo de investigación que se caracteriza por la indagación empírica de los problemas de estudio en sus propios contextos naturales, los que son abordados simultáneamente a través de múltiples procedimientos metodológicos. Por su parte Délano (Cfr. Moulián, 2002) sostiene que el estudio de casos se caracteriza por: a) una aspiración holística, el esfuerzo de comprender los hechos socioculturales en el contexto social en que se desarrollan, y b) la asunción de la perspectiva emic, es decir, la comprensión de los hechos socioculturales desde el punto de vista de los propios actores.

Dado que el análisis de caso se caracteriza por la utilización de una variedad de técnicas y tomando en consideración nuestra opción por una semiótica abierta, intertransdisciplinaria que propugna la utilización de múltiples enfoques y metodologías es que nos pareció pertinente seleccionar y combinar distintas técnicas de recolección de datos. Las principales técnicas de investigación que hemos empleado son: a) entrevista en profundidad, b) entrevista semiestructurada, c) observación participante, d) descripción etnográfica, e) análisis bibliográfico y f) aplicación del Modelo Sociosemiótico, -esquematizado y descrito más abajo-, como soporte de esta misma metodología.

En lo relativo al corpus, en esta investigación en que utilizamos metodología aproximada a la semiótica (cultural-comunicacional), está constituido por discursos sociales que, básicamente, constituyen un grupo de diez entrevistas que son consideradas útiles para justificar las explicaciones que nos proponemos en las hipótesis. Dichas entrevistas se han aplicado a devotos del Arcángel San Miguel y que, además presentan un fuerte arraigo y sentido de pertenencia a su comunidad, por lo que pueden informar con mucha propiedad, especialmente el sentido que le confieren al Santo Patrono de la ciudad. Además, hemos efectuado una entrevista en profundidad al sacerdote holandés, Padre Antonio Van Kessel, quien ejerció su apostolado por 28 años en la comuna de Calbuco y que se constituye en un informante idóneo para nosotros a fin de adquirir conocimiento profundo sobre el rito novenario. También, este sacerdote conoce los fundamentos doctrinarios relativos a la adoración a los santos. Lo último, con el propósito de efectuar una operación analítica contrastiva entre el sentido ortodoxo católico y el sentido conferido por los fieles a la figura de San Miguel y su ceremonia ritual de veneración y así, determinar el discurso reinterpretativo sincrético que postulamos. Entendemos con Magariños de Morentin (1996) por operación analítica contrastiva aquella que relaciona las marcas perceptuales identificadas en determinado discurso social con otras marcas perceptuales identificadas en otro determinado discurso social, contemporáneo del primero. 


\subsection{EXPLICACIÓN DEL MODELO SOCIOSEMIÓTICO PARA UNA LECTURA INTERPRETATIVA}

\section{EL MODELO SOCIOSEMIOTICO}
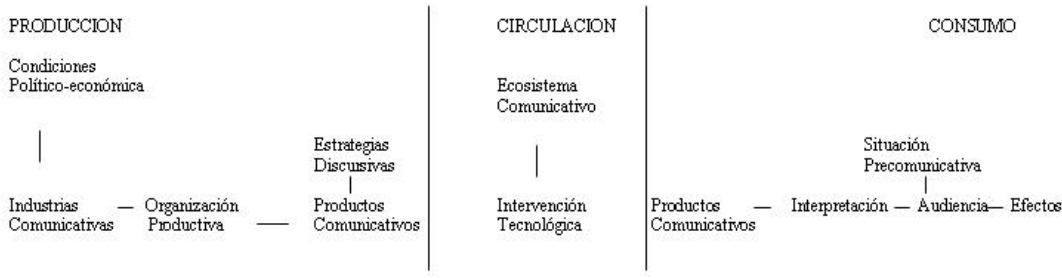

Fuente: Los Modelos de la Comunicación. Miquel Rodrigo Alsina (1995)

Dados los objetivos planteados para nuestro trabajo, nos hemos propuesto aplicar del modelo solo la fase que se refiere al consumo simbólico de los mensajes por parte de los usuarios. Asumir la aplicación de todas las fases del modelo excedería con creces los límites que emanan de la propia naturaleza y especificidad de la presente investigación. No obstante, estamos conscientes que todas las fases del modelo sociosemiótico están interrelacionadas, por lo que un cambio producido en una de ellas necesariamente condiciona a las demás. Esto último nos obliga a dar, aunque sea una visión sucinta de la globalidad del modelo, pero con un énfasis en la explicación de la fase referida al consumo de los mensajes. Sin embargo, procuramos dar un grado de aplicabilidad en nuestro trabajo a todas las fases del modelo, pero, como es evidente, con una fuerte atención en la fase del consumo, específicamente en el factor de la interpretación, por ser central a la hora de introducirnos en la comprensión del proceso de reinterpretación sincrética que se produce en torno a la figura de San Miguel.

Para nuestro autor el objeto de estudio de la sociosemiótica es la comunicación de masas. La comunicación masiva es un proceso que consta de tres fases: producción, circulación y consumo. La producción corresponde a la etapa de creación del discurso de los mass media, etapa que se encuentra constituida por las condiciones políticoeconómicas, las industrias de comunicación, la organización productiva y los productos comunicativos. Todos estos elementos se interrelacionan y condicionan mutuamente. En tanto, la circulación se efectúa cuando el discurso entra en el mercado competitivo de la comunicación de masas. En esta fase los conceptos más relevantes son la intervención tecnológica y el ecosistema comunicativo. La intervención de la tecnología interesa desde el punto de vista sociosemiótico en tanto transformadora de los discursos y, además, los efectos sociales que lleva aparejada dicha tecnología. El ecosistema comunicativo lo constituiría el espacio público en el que circulan los discursos de los mass media. 


\section{CALBUCO (CHILE)}

Pasemos ahora a la interpretación. Junto con Rodrigo Alsina estimamos que la interpretación es el elemento central del consumo de los productos de los medios masivos de comunicación, $y$, en particular, es clave en el proceso de apropiación del sentido de la figura de San Miguel y su fiesta de adoración que nos ocupa, habida consideración que esta última la concebimos también como una expresión popular de comunicación masiva. Por otro lado, nuestro autor sostiene que es más oportuno, en la actualidad, hablar de interpretación que de decodificación y, además, plantea con Eco (1981) que se debe distinguir el uso libre de un texto como estímulo imaginativo y la interpretación de un texto abierto. La noción de interpretación, para Eco, supone siempre una dialéctica entre la estrategia del autor y la respuesta del lector modelo. Es incuestionable que puede darse un uso libre, aberrante, intencionado y malicioso de los textos.

Es primordial detenernos con Rodrigo Alsina (1995) en la distinción que se da entre el uso y la interpretación de un texto. La diferencia entre el uso y la interpretación radica en la aceptación social mayoritaria o no de la lectura realizada. Cuando una comunidad determinada considera que el sentido que se le da a un texto es más o menos aceptable estaríamos ante una interpretación. Cuando el significado va más allá del sentido común o comunitario estaríamos ante un uso. Es decir que, aunque puede darse un uso particular de cualquier mensaje, a nivel social hay un cierto consenso en el tipo de interpretación legitimable de los textos (Rodrigo Alsina, 1995).

En palabras nuestras, podemos sostener entonces que el proceso de reinterpretación que se observa, tanto de la figura de San Miguel como de su fiesta de veneración, es un proceso legitimado por la comunidad usuaria de este tipo de ritos tan característicos de la religiosidad popular, en tanto actividad semiotizada cuya impronta la constituye, precisamente, la agregación de sentidos a las expresiones religiosas de la iglesia lo que posibilita un proceso semiótico de sincretismo.

\section{SEMIOSIS ILIMITADA: HACIA UNA LECTURA DEL ESTALLIDO DEL SENTIDO HEGEMÓNICO}

\subsection{PRODUCCIÓN, CIRCULACIÓN Y CONSUMO SIMBÓLICO EN LA RELIGIOSIDAD POPULAR}

A lo largo del proceso comunicativo de construcción simbólica (producción, circulación y consumo), desplegado por la religiosidad popular -que se encuentra materializada aquí en la veneración al Arcángel San Miguel-, se observa cómo el proceso de semiosis ilimitada -que aquí relacionamos con el proceso de reinterpretación- posibilita que se produzca un ilimitado desplazamiento de un signo a otro. Esta contaminación sígnica hace 
que proliferen las posibilidades de intercambio y confluencia entre elementos diversos. Cada mixtura sígnica hace que estalle el sentido hegemónico ortodoxo incorporando al relato sincrético -en contraste con la transmisión o fiel reproducción- una explosión de sentidos, experiencias y simbolizaciones que caracterizan una manera singular de apropiación de la fe.

El proceso de producción o creación del discurso religioso -en tanto fiesta de veneración al Arcángel San Miguel-nos remite como antecedente a la doctrina tradicional de la iglesia. Sin embargo, es en la época colonial de la historia de Latinoamérica que se produce su implantación como pauta cultural externa: los aborígenes aceptan esta expresión cultural foránea, pero la someten a un proceso de resignificación sincrética. Podemos afirmar que la iglesia como "sujeto semiótico" (Landowski, 1987, cfr. Rodrigo Alsina, 1995) -que decodifica, interpreta y codifica- se constituye en un prolífico polo de producción sociosemiótica por cuanto produce y emite una variada gama de mensajes, de mundos posibles y creíbles mediante la fe.

Desde la circulación, podemos constatar que los productos comunicativos del ámbito religioso se insertan en un sistema de discursos de distinta índole, propiamente en un mercado de la comunicación pública, lo que para Rodrigo Alsina (1995) sería "un ecosistema comunicativo [...] el espacio público en el que circulan los discursos de los mass media y en el que éstos desarrollan complejas relaciones" (Rodrigo Alsina, 1995: 120). En las sociedades multiculturales, terciarias, del capitalismo avanzado, globalizadas, el discurso religioso ha perdido, paulatinamente, importancia debido a una forma de secularización sociológica que es producto de un proceso de desencanto que ha sufrido el mundo occidental, como consecuencia del avance de la civilización técnica (Marzal, 1983 y 2002).

Para Pierre Bourdieu (2006), el campo religioso es un aparato de dominación simbólica. El dominio está marcado por la monopolización de la circulación y uso del capital simbólico referido a la especialización de los secretos de salvación (pensemos cómo los sacerdotes han gestionado la exclusividad de la consagración, la comunión, la interpretación bíblica, los santos oleos, la confesión, etcétera). Este monopolio es ejercido por un cuerpo sacerdotal de especialistas, que gozan del reconocimiento y la legitimidad social de ser los detentores exclusivos de los saberes de salvación.

En el proceso del consumo del ritual venerativo a San Miguel -entendida esta festividad en términos amplios como un proceso de comunicación- se debe tener en cuenta como categoría de análisis el contexto macro y micro social en que se desarrolla la apropiación de sentidos por parte de los fieles. En términos macrosociales, el tipo de sociedad en el que se produce el proceso comunicativo que abordamos la caracterizamos junto con Alvarado Borgoño (2004) como una sociedad en que gradualmente han penetrado los valores de la globalización mercantil, de la influencia relevante de los mass media y de 


\section{CALBUCO (CHILE)}

la agilización de los medios de transporte. La constitución de lo moderno en América Latina posee la peculiaridad de expresarse desde un fenómeno que, a decir de García Canclini (1993), es el de la hibridación, entendiendo por tal un estado de cosas en el cual simultáneamente convivimos con valores y prácticas propias de la modernidad y con otras que pertenecen a lo más profundo de las formas culturales tradicionales latinoamericanas, agudizándose esto por un proceso peculiar de sincretización en el cual ni lo tradicional ni lo moderno se presentan químicamente puros (Alvarado Borgoño, 2004).

Otro de los elementos centrales en la operación semiótica de consumo de todo producto comunicativo lo constituye la competencia comunicativa del receptor para activar todos los sistemas semióticos que están a su alcance como miembro particular de una comunidad sociocultural. En el caso de la fiesta de tributo a San Miguel creemos que la competencia sociocultural para crear un proceso reinterpretativo viene dada, a nuestro entender, por la existencia de tres cauces complementarios: la tradición, la oralidad y la participación en la teatralidad de la fe (Andrade, 1997). Respecto a la tradición es recurrente en las entrevistas a los devotos reportar que los mayores les inculcaron la fe icónica al llevarlos desde chicos a las fiestas religiosas. La oralidad nos remite a las múltiples historias y mitos en torno a la figura del Santo Patrono de Calbuco, por ejemplo, que, mediante el expediente de la transmisión boca a boca, se aprende que se hizo pesado o se hizo fuerte para que no lo trasladaran a las afueras de la ciudad de Calbuco, manifestando así su deseo de permanecer en dicho lugar; o que a veces se taima cuando se rehúsa a participar en la procesión. La participación en la teatralidad de la fe constituye una instancia social y estética en que se institucionaliza todo un bagaje de conocimientos del "sistema sígnico que debe ser decodificado por los que participan y observan su desarrollo" (Andrade, 1997: 102). El proceso reinterpretativo se instala, entonces, como una competencia adquirida por el usuario de la fe popular que necesita desdeificar y terrenalizar el objeto de su culto, codificado por la institución eclesial como intemporal, inmaterial y trascendente.

En el proceso cultural de reinterpretación sincrética, con motivo de la veneración al general de las milicias celestiales, postulamos un doble proceso de apropiación de sentidos: por un lado, el Arcángel San Miguel, como figura central del rito celebrativo icónico, es motivo de una resignificación por parte de los devotos y, por otro, como consecuencia del proceso anterior, la fiesta novenaria propiamente tal adquiere para los devotos un sentido distinto y complementario a lo estrictamente religioso. 


\subsection{EL ARCÁNGEL SAN MIGUEL Y SU INTERPRETACIÓN ECLESIAL}

Los católicos veneran a San Miguel desde la iglesia primitiva como el ángel que derrotó a Satanás y sus seguidores y los echó del cielo con su espada de fuego. Es tradicionalmente reconocido como el guardián de los ejércitos cristianos contra los enemigos de la Iglesia y como protector de los cristianos contra los poderes diabólicos, especialmente a la hora de la muerte.

Para la Iglesia, el nombre Miguel significa ¿Quién como Dios?, según se desprende del punto de vista de algunas congregaciones religiosas, como la de las Siervas de los Corazones Traspasados de Jesús y María. Satanás tiembla al escuchar su nombre, ya que le recuerda el grito de noble protesta que este arcángel manifestó cuando se rebelaron los ángeles. San Miguel manifestó su fortaleza y poder cuando peleó la gran batalla en el cielo. Por su celo y fidelidad para con Dios gran parte de la corte celestial se mantuvo en fidelidad y obediencia. Su fortaleza inspiró valentía en los demás ángeles quienes se unieron a su grito de nobleza: ¿Quién como Dios? Desde ese momento se le conoce como el capitán de la milicia de Dios, el primer príncipe de la ciudad santa a quien los demás ángeles obedecen².

Para el padre Antonio Van Kessel el discurso doctrinal de la iglesia "acepta estos rituales de adoración a los santos porque son un camino" (para llegar a Dios). La iglesia concibe a los santos como meros "intercesores" entre Dios y los hombres".

\subsection{REINTERPRETACIÓN SINCRÉTICA DEL ARCÁNGEL SAN MIGUEL}

La religiosidad popular privilegia, a nuestro juicio, en la fase del consumo, el nivel subjetivo y participativo de la recepción. El individuo no solo se apropia de los ritos, sino que genera nuevas rutas interpretativas asumidas como un bricolage en que se da cuenta de un itinerario personal de consumo, pero que está en alguna medida legitimado por una comunidad que construye intersubjetivamente la realidad. Las personas van generando nuevos caminos de consumo religioso para satisfacer utilitariamente sus necesidades físicas, emocionales y espirituales, generando sentidos que son concordantes con sus historias personales y con el contexto sociocultural en que se encuentran insertas. Para lo cual, desarrollan operaciones discursivas que activan procesos de reinterpretación mediatizados de las formas religiosas católicas.

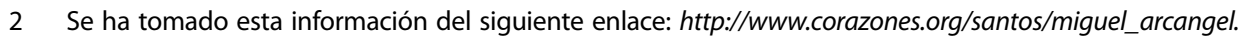
htm [15/12/2016] 
Como señalan Rostas y Droogers (1995), en la religiosidad popular se viven permanentemente los procesos de redefinición y reinterpretación del sentido práctico de la religión; se negocian y confrontan constantemente las relaciones de poder de dominación y resistencia, tanto entre la iglesia oficial y los creyentes, como entre las relaciones de clase.

Estamos ante una de las características más sólidas de la religiosidad popular: la visión utilitaria de los personajes celestiales como es el caso del Arcángel San Miguel. En el fondo, lo que se busca es la personalización de las relaciones: ante los insondables, abstractos y complicados misterios de la teología, el devoto necesita buscar los cauces para conseguir el acercamiento de esas figuras a un plano más humano, más cercano a su realidad, a sus pasiones y sentimientos, a los que poder solicitar su intermediación ante la lejana divinidad.

Además, en la religiosidad popular, encontramos un fenómeno que resulta interesante para el desarrollo de nuestro trabajo y que lo entendemos con Isambert (Cfr. Ariño, 2002) como un realismo simbólico generalizado que habla de una presencia real de la trascendencia en los objetos consagrados (extensivamente en las imágenes de los santos).

En términos concretos para nuestra investigación: esta tendencia a interpretar que la imagen material de San Miguel es realmente el arcángel posibilita que los devotos crean ver un proceso de transubstanciación por medio del cual esta entidad celestial se corporeiza en la fisicidad del ícono. Creemos que esta interpretación realista por parte de los devotos genera a nivel simbólico-comunicacional el uso de una estrategia comunicativa humanizante en torno al Arcángel San Miguel.

En efecto, los devotos no dudan en usar el fenómeno retórico de la personificación como recurso para atribuirle una condición humana a este arcángel y así, lograr una cercanía utilitaria en lo material y espiritual. Por ello, no es de extrañar que los devotos atribuyan cualidades humanas al arcángel al expresar-como ya lo dijimos-que transmite su temperamento al no aceptar, contradictoriamente, participar en la procesión en su honor: "se taima" (Sra. Irma Paredes); "dicen que una vez los curas de Ancud querían llevarlo para allá, pero cuentan que el santo se hizo tan pesado que no hubo caso que pudieron moverlo" (Don Segundo Garay); "no lo pudieron mover ni entre cinco personas" (Don César Miranda). También, advertimos - para referirse a San Miguel- la utilización de diminutivos como una forma familiar de demostrar afecto y empatía hacia él: "San Miguelito"; "santito"; "le quebraron su manito" (Sra. Norma Mancilla). La estrategia comunicacional humanizante a nivel lingüístico es un correlato de lo que también ocurre en la procesión de San Miguel: la imagen venerada recorre en andas las calles, en donde es escoltada por una multitud de fieles acompañados de imágenes traídas desde las comunidades asistentes a la fiesta patronal. Estos cantan alabanzas en un coro cacofónico 
donde cada grupo celebrante entona canciones a su veneración, entremezclándose los sones. La movilidad humana que adquiere la efigie y la fiesta que produce un intenso goce sensorial en el devoto no hace otra cosa que vivificar al santo arcángel y de paso, aumentar en el participante devoto su empatía por él.

Consecuencialmente, en la misma línea del utilitarismo y realismo de la religiosidad popular, el devoto refuncionaliza -en este caso- la figura del Arcángel San Miguel ya codificada por la iglesia como institución. Como sujeto semiótico la iglesia se ha encargado de codificar dogmáticamente las marcas semánticas que corresponden a la entidad que conocemos como Arcángel San Miguel. A saber: protector de los cristianos contra los poderes malignos, guardián de los ejércitos cristianos e intermediario entre Dios y los hombres. Entonces, al predicar de San Miguel transforma en un juicio semiótico estas determinadas marcas semánticas, entendiendo con Eco por juicio semiótico a "un juicio que predica de un contenido determinadas marcas semánticas que ya le ha atribuido un código preestablecido" (Eco, 1988: 238). La mencionada refuncionalización -fenómeno tan característico de la religiosidad popular- resignifica el dogma incorporando sincréticamente a San Miguel marcas que no le ha atribuido previamente el código, lo que se conoce como juicio factual (Eco, 1988). Sin embargo, el juicio factual para la religiosidad popular se transforma en un juicio semiótico, porque los devotos institucionalizan aquellas marcas semánticas y en una representación enciclopédica del Arcángel San Miguel figurarán dichas características que están legitimadas socialmente a través de una construcción intersubjetiva de la realidad.

El proceso de significación -o resignificación- que realizan los devotos nos permite afirmar con Eco que la movilidad del espacio semántico hace que los códigos cambien mediante procesos, lo que impone a la actividad de producción de signos y de interpretación de los textos la necesidad de una plus-codificación. El intérprete de un texto está obligado a un tiempo a desafiar los códigos existentes y a lanzar hipótesis interpretativas que funcionan como formas tentativas de nueva codificación (Eco, 1988).

En tal sentido, creemos que el acto reinterpretativo producido por los devotos genera sentidos que el código no contemplaba. Sin embargo, como hemos sostenido, estas reinterpretaciones producen en este caso nuevos códigos, mediante procesos de hipercodificación ${ }^{3}$ : el devoto popular, dadas determinadas unidades codificadas la codificación relativa a los santos, por ejemplo- las analiza o interviene en unidades menores a las que asigna nuevas funciones semióticas produciéndose una innovación, pero que luego se convencionaliza para un grupo de creyentes usuarios de la religiosidad popular, en contraposición a lo aceptado por la religión oficial.

3 Para Eco (1988) una hipercodificación consiste en que, a partir de una regla anterior, se propone una regla adicional para una complicación muy particular de la regla general. 


\section{CALBUCO (CHILE)}

El proceso de refuncionalización del Arcángel San Miguel y de su fiesta venerativa se encuentra inmerso en la tendencia utilitarista y realista de la religiosidad popular, en el entendido que el usuario o consumidor de esta manifestación religiosa recodifica sincréticamente las funciones espirituales del santo arcángel y las semiotiza otorgándole un carácter más cercano, terrenal y, por ende, funcional a sus necesidades materiales y espirituales mediata, a diferencia del discurso ortoxo católico que semiotiza a San Miguel en un plano intemporal como intercesor entre Dios y los hombres.

En el plano empírico, a través de entrevistas, hemos registrado una serie de marcas semánticas atribuidas al Patrono de la ciudad de Calbuco (sur de Chile). Para visualizar en los respectivos discursos sociales las denotaciones producidas y resaltar el carácter reinterpretativo y sincrético del discurso religioso popular proveeremos un cuadro comparativo para efectuar la operación analítica contrastiva de los sentidos producidos por los respectivos sujetos semióticos.

\begin{tabular}{|l|l|}
\hline $\begin{array}{l}\text { San Miguel y las denotaciones } \\
\text { del Discurso ortodoxo católico }\end{array}$ & $\begin{array}{l}\text { San Miguel y las denotaciones del Discurso religioso } \\
\text { popular }\end{array}$ \\
\hline $\begin{array}{l}\text { "Protector de los cristianos } \\
\text { contra los poderes malignos"; }\end{array}$ & "Prodigador de bienestar y prosperidad económica"; \\
"intermediario entre Dios y los & domésticos"; "sanador de graves enfermedades como \\
hombres". & el cáncer y problemas vasculares"; "propiciador de la \\
natalidad"; "padre que protege las personas"; "gran \\
protector de la ciudad de Calbuco" (mitigó los efectos del \\
terremoto registrado en el sur el año 1960 y amainó el \\
incendio que arrasó gran parte del centro de la ciudad el \\
año 1945); "compañero para las personas solitarias", "dueño \\
de la vida y la muerte", etc.
\end{tabular}

Fuente: creación del autor

Como podemos constatar, la religiosidad popular genera rutas de consumo socializadas como eficaces y más terrenales, la que podemos conceptualizar como un espacio de consumo simbólico en que, como praxis social, redefine, reinterpreta y negocia.

\section{CONCLUSIONES}

La presente investigación pretende instalar una línea teórico-crítica desde las teorías de la comunicación que haga posible una lectura interpretativa de un fenómeno cultural tan característico de la religiosidad calbucana como lo es la devoción profesada a su Santo Patrono: el Arcángel San Miguel. Para este propósito, resultó provechosa la 
utilización del modelo sociosemiótico propuesto por el comunicólogo catalán Miquel Rodrigo Alsina (1995) para analizar interpretativamente desde el ámbito de la producción, circulación y preferentemente desde el consumo las manifestaciones rituales en torno al Arcángel San Miguel y la manera cómo los sujetos hacen uso de ellas. Al adentrarnos en la lectura interpretativa de nuestro objeto de estudio -la reinterpretación de la figura de San Miguel en su fiesta de adoración- hemos podido acceder a las claves que dan cuenta de las características centrales de la religiosidad popular como fenómeno cultural hispanoamericano, como lo probaremos más adelante. Antes, nos interesa precisar que nuestra interpretación, desde la semiótica, forzosamente se encuentra mediada por la interpretación de un signo o un texto (en este caso el rito venerativo hacia la figura central de la fiesta patronal) realizada por los devotos.

Las notas principales de la religiosidad popular que practica el devoto calbucano del Arcángel San Miguel las podemos sintetizar en seis características pesquisadas en nuestro estudio empírico: (i) nivel subjetivo y participativo de la recepción; (ii) visión utilitaria de los personajes celestiales, por ende, se busca personalizar las relaciones; (iii) tendencia al realismo simbólico generalizado, en consecuencia, se posibilita una interpretación realista de la imagen (Isambert, cfr. Ariño, 2002); (iv) uso de una estrategia comunicativa humanizante; (v) refuncionalización de la fiesta ritual y su figura central, y (vi) se concibe la participación ritual como un servicio de contraprestaciones.

La religiosidad popular, en tanto discurso social, produce la significación de los ritos tradicionales católicos en forma diferencial y complementaria con el discurso social de la ortodoxia de la iglesia, mediante la reinterpretación o recodificación del componente semántico. La actividad productora de sentido del devoto popular abre las posibilidades al juego infinito de generar -a partir del código dogmático- nuevas formas de apropiación de la experiencia religiosa, definiendo así el sincretismo como su rasgo principal. Dicha semiosis se hace posible en la medida que las personas son productoras de significados y, en tal sentido, redefinen y reinterpretan los discursos sociales oficiales adaptándolos a su propia circunstancia personal y sociocultural, lo que posibilita un alejamiento simbólico del poder discursivo hegemónico para buscar nuevas fuentes de poder desde la periferia.

En la presente investigación, consideramos que ha tenido un grado importante de éxito la aplicación de la operación analítica contrastiva, en cuanto estructura interpretativa que nos ha permitido identificar las denotaciones producidas en los discursos sociales, por ende, nos ha remitido a la producción de significación -diferencial y complementaria- del discurso religioso popular con respecto al discurso de la iglesia, confirmando así su carácter reinterpretativo y, consecuencialmente, sincrético como lo habíamos postulado en una de nuestras hipótesis. 


\section{REFERENCIAS BIBLIOGRÁFICAS}

ALVARADO BORGOÑO, M. (1995). Sincretismo religioso latinoamericano y pensamiento católico: la ciencia social como constructora de una interpretación polifónica. [Santiago]: Universidad Católica Blas Cañas. Serie de investigaciones, núm. 2.

(2004). Ensayos de análisis cultural. (Aportes sobre la conformación del discusrso en torno a la diversidad en las ciencias humanas y sociales latinoamericanas). Valparaíso: Universidad de Playa Ancha-Facultad de Humanidades.

ANDRADE, E. (1997). "La teatralidad de la fe: el culto al Jesús Nazareno de Caguach". Gestos. Teoría y Práctica del Teatro Hispanoamericano 12.24, 101-118.

ARIÑO, A. (2002). "Fiesta y ritual. Dos conceptos básicos". Seminario "Patrimoni etnològic, cultura i memòria: nous materials per a l'acció local", Barcelona: Diputación de Barcelona,

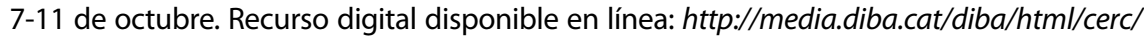
interaccio2002/seminar/s2/marcseminar2_ca.htm [09/12/2016].

BAJTIN, M. (1989). Teoría y estética de la novela. Madrid:Taurus.

BARROS ARANA, D. (1909). Historia General de Chile. Santiago de Chile: Ediciones Universitarias. BARRUEL, E. (1997). Los fiscales de Chiloé. Una ruta devocional. Santiago: Ediciones Orígenes. BERGENHENEGOUWEN, J. (s. a.). Libro Historial. Manuscrito inédito. Parroquia de Calbuco. BERGER, P.\& LUCKMANN, T. (1979). La construcción social de la realidad. Buenos Aires: Amorrortu. (1994). Modernidad, pluralismo y crisis de sentido. Barcelona: Paidós.

BOURDIEU, P. (2006). "Génesis y estructura del campo religioso". Relaciones. Estudio de historia y sociedad, XXVII.108, 29-83. Disponible en línea en: http://www.redalyc.org/articulo. oa?id=13710803 [15/12/2016]

ECO, U. (1981). Lector in fábula. Barcelona: Lumen. (1988). Tratado de semiótica general. Barcelona: Lumen.

FERNÁNDEZ DE PAZ, E. (2006). “Religiosidad popular andaluza. Testimonio de un patrimonio que identifica". Revista PH 33, 192-199. Disponible en línea: http://www.iaph.es/revistaph/ index.php/revistaph/article/view/1106/1106\#.WEqXV7LhDIV [09/12/2016].

GARCÍA CANCLINI, N. (1993). El consumo cultural en México. México: Consejo Nacional para la Cultura y las Artes.

GEERTZ, C. (2000). La interpretación de las culturas. Gedisa, Barcelona.

MAGARIÑOS DE MORENTIN, J. (1996). “Esbozo semiótico para una metodología de base en las ciencias sociales". En Fundamentos lógicos de la semiótica y su práctica. Buenos Aires: Edicial, 247-300.

MARTíNEZ, M. (2004). "Apariciones, religiosidad popular y contracultura de la Ilustración". Ciencias Sociales Online III.1, 76-85. Disponible en línea: https:/www.yumpu.com/es/ document/view/50336151/apariciones-religiosidad-popular-y-contracultura-de-lailustracian/6 [09/12/2016] 


\section{JULIO SÁEZ GALLARDO}

MARZAL, M. (1983). La transformación religiosa peruana. Lima: Pontificia Universidad Católica del Perú/Fondo Editorial.

(2002). La tierra encantada. Tratado de antropología religiosa de América Latina. Lima: Trotta/Fondo Editorial PUCP.

MINGUEZ, V; RODRIGUEZ, I.; GONZALEZ, P. y CHIVA, J. (2012). La fiesta barroca: los virreinatos americanos (1560-1808). Castellón de la Plana: Universitat Jaume I/Universidad de las Palmas de Gran Canaria.

MOULIÁN, R. (2002). Magia, retórica y cognición. Un estudio de textos mágicos y comunicación ritual. Santiago: LOM. (2010). Gozos de Santo: fiesta, ecumenismo y heteroglosia. Kultrún: Universidad Austral de Chile.

O'HIGGINS, T. (1949). “Diario de viaje del Capitán Don Tomás O"Higgins". Revista Chilena de Historia y Geografía 101, 42-97.

OLIVARES, M. (1874). Historia de la Compañía de Jesús en Chile (1593-1736). Santiago de Chile: Imprenta Andrés Bello.

RODRIGO ALSINA, M. (1995). Los modelos de la comunicación. Madrid: Tecnos.

ROSTAS, S. y DROOGERS, A (1995). “El uso popular de la religión en América Latina: una introducción". Alteridades 5.9, 81-91. Disponible en línea: http://www.redalyc.org/articulo. oa?id=74711352008 [09/12/2016].

TAMPE, E. (1983). Desde Melipulli hasta Puerto Montt. Trayectoria de ciento treinta años. Tomo I. Santiago de Chile: s. n.

URBINA, R. (1990).“La rebelión indígena de 1712: Los tributarios de Chiloé contra la encomienda”. Tiempo y Espacio 1.1, 73-86.

VALENZUELA, V. H. (2005). “San Miguel Arcángel y la serpiente: comunicación e interpretación en manifestaciones culturales arcaicas de nuestra sociedad". F@ro: revista teórica del Departamento de Ciencias de la Comunicación 1-2, 175-186. Disponible en línea: http://web. upla.cl/revistafaro/n2/02_valenzuela.htm [09/12/2016]

VÁZQUEZ DE ACUÑA, I. (1994). Santería de Chiloé. Ensayo y Catastro. Santiago: Antártica.

Recibido el 26 de abril de 2016.

Aceptado el 25 de noviembre de 2016. 